MOROZ YU.

Yuri Kondratyuk National Technical University, Poltava, Ukraine

\title{
AXIOLOGICAL ASPECTS OF EDUCATION OF RECREATIONAL CULTURE OF STUDENT YOUTH
}

The article reveals the problems of attracting modern student youth to the cultural forms of leisure organization and presents the education of young people and girls of recreational culture as one of the means of activating this process.

Recreational student culture is seen as voluntary physical activity using physical exercises aimed at improving psychophysiological performance; entertainment and versatile improvement of students' personality in the process of vocational training; as one of the functions of culture related to the restoration of one's spiritual powers, the renewal and the restoration of one's spiritual potential, and the like. Health is the leading value in most definitions, the preservation and restoration of which serves the purpose of recreational activity.

The author analyzes two groups of factors of low recreational culture of the modern Ukrainian student (mentalenvironmental and factor of unrecognized value) and outlines ways of its upbringing on value basis.

Keywords: high school, student youth; recreation; recreational culture; recreational effect; leisure; recreation, education; health; social values; personal values

Стаття надійшла до редакції 12.04.2019 p.

удК 378.011.3-051

DOI: https://doi.org/10.33989/2075-146x.2019.23.183242

НІНА ПИВОВАР

Полтавський національний педагогічний університет імені В.Г. Короленка

\section{ДІАГНОСТИЧНІ МОЖЛИВОСТІ ПРОФЕСІЙНОГО ІДЕАЛУ В СИСТЕМІ ДОПРОФЕСІЙНОЇ ПІДГОТОВКИ ВЧИТЕЛЯ НОВОї УКРАЇНСЬКОЇ ШКОЛИ}

\begin{abstract}
У статті розглядаються можливість визначення та практичної інтерпретації рівня сформованості професійного ідеалу майбутнього вчителя як головного мотиву самовдосконалення у різних системах допрофесійної підготовки.
\end{abstract}

Ключові слова: професійний ідеал; допрофесійна підготовка вчителя; професійна спрямованість студентів; математична модель професійного ідеалу

Постановка проблеми. Сьогодні в освіті назрівають нові глобальні зміни, для їх реалізації однією з передумов $\epsilon$ боротьба за талановитого й креативного студента педагогічного навчального закладу, хоча практика діяльності вищої педагогічної школи в останні роки досить часто вказує на те, що відбір абітурієнтів у ЗВО носить випадковий характер, а прийняті критерії не забезпечують у них виявлення схильностей та здібностей до педагогічної діяльності. Тому вважаємо доречним у нових суспільно-політичних умовах проаналізувати успішний досвід ПНПУ імені В. Г. Короленка у 80-х роках минулого століття у рамках реалізації Цільової комплексної програми «Вчитель», де пропонувався відбір абітурієнтів у педагогічні навчальні заклади здійснювати шляхом ранньої підготовки учнів через включення їх у діяльність із реальним педагогічним змістом. Цей досвід базується на глибокому вивченні та всебічному врахуванні психологічних засад професійної підготовки вчителя, а отже, заслуговує на увагу, аналіз із оновлених позицій та модернізацію у зв'язку з новими історичними умовами i побудовою Нової української школи.

Аналіз досліджень і публікацій, на які спирається автор. Аналіз відповідних наукових джерел, сучасної системи формування професійних орієнтацій школярів показує, що робота у цій галузі проводилася вже давно. Про це свідчать дані дослідження А.М. Баскакова, В.Б. Бондаревського, Л.Г. Борисової, І.А. Вельковської, М.Д. Конаєва, С.П. Крягжде, В.Ф. Сахарова, В.О. Сластьоніна. У 80-х роках ХХ ст. активізувалась робота щодо втілення довготривалих форм роботи з майбутніми абітурієнтами, зокрема: школи юних педагогів, факультативи майбутніх учителів та ін., випускники яких швидше й легше за інших адаптувалися до навчання у ВНЗ. Аналіз праць вітчизняних та зарубіжних учених (Ю.К. Васильєва, М.М. Заброцького, М.С. Горностая, Л.А. Михащенка, І.Л. Кобзаря, Є.І. Ромашкової, В.І. Чаполєва) дозволив визначити коло завдань, що стоять перед системою допрофесійної підготовки, а також сформулювати основні вимоги до різних форм роботи зі школярами 3 метою професійно-педагогічної орієнтації та ознайомлення їх із специфікою педагогічної діяльності і принципами організації. Знайомство 3 роботами різних авторів (В.В. Анісімова, Н.П.Волкової, Т.А. Горюнова, П.А. Жильцова, Л.Д. Денисяко, Т. Дербішалієва, Л.А. Бойко, Л.А. Ковальової, З.Г. Сазонової, Я.Ф. Райца, А.С. Адамчика, В.Н. Кухарева, С.В. Краєвої, А.Л. Михашенка та ін.) дозволило виявити цікаві й результативні 
форми, які використовуються для організації профорієнтаційної роботи у допрофесійній підготовці майбутнього учителя. В.В. Антиповим, А.А. Гоброідзе, Л.Д. Денисяко, П.А. Жильцовим, В.Я. Запольських, Г. М. Каржаспіровою та ін. накопичений значний досвід організації роботи факультативів майбутнього учителя (ФМУ), обгрунтована їх ефективність. Цей досвід був покладений в основу використаної у цьому дослідженні системи допрофесійної підготовки.

Метою статті $\epsilon$ аналіз досвіду застосування успішно апробованих форм організації профорієнтаційної роботи 3 учнями на вчительську професію засобами вивчення стану сформованості їхніх професійних ідеалів 3 урахуванням ефективного вітчизняного досвіду.

Виклад основного матеріалу. Підготовка вчителя до виконання своїх складних функціональних обов'язків процес, який не може обмежуватися лише ЗВО. Вирішення цієї проблеми потребує чіткої координації діяльності усіх ланок педагогічної системи - лише за такої умови можна на нього розраховувати. Одним із важливих напрямків цієї роботи є формування у школярів зацікавленості педагогічною професією, що сприяє підвищенню їх готовності до свідомого вибору професії і суттєво впливає на поліпшення підготовки вчительських кадрів.

Якщо більшість студентів у процесі навчання все ж знаходять своє покликання у праці вчителя, то сьогодні чимало з них змінюють первинну спрямованість, з тих чи інших причин відмовляючись від зробленого вибору. У попередні роки відзначалося, що особливо інтенсивно цей процес проходить після педагогічної практики, тобто після зіткнення з першими труднощами чи навіть невдачами. Але нині навіть учні молодших курсів нерідко заявляють про розчарування в обраному фахові вже в процесі теоретичної підготовки.

Дослідження професійного ідеалу, проведені науковим колективом, до якого входив автор статті, на початку 80 х рр. минулого століття, дали змогу виокремити деякі закономірності, що носять об'єктивний характер. Це дає змогу спиратися на їхні результати і в нинішніх умовах, коли підготовка вмотивованого вчителя для Нової української школи вимагає істотного вдосконалення нині діючих засад здобуття вищої педагогічної освіти.

У нашому дослідженні ми враховували дані В. А. Семиченко, згідно з якими для студентів педагогічних навчальних закладів характерні сім основних типів професійної спрямованості: 1) педагогічна; 2) похідна від професії; 3) похідна від спеціальності; 4) непрофільна; 5) наукова; 6) амбівалентна; 7) невизначена. Причому, окремі види спрямованості можуть суттєво видозмінюватися залежно від умов навчання і життя студентів. Виявлено, що найбільш несприятливим для індивідуального розвитку є невизначений тип спрямованості, коли у студентів немає чітких критеріїв професійного росту, вони інфантильні у спецпідготовці, їхня діяльність підпорядковується впливу різних локальних факторів, а розвиток особистості здійснюється недостатньо ефективно (Семиченко, 1989).

У ході проведеного дослідження студенти різних курсів зазначали, де й ким хотіли б вони працювати після закінчення ЗВО. При цьому фіксувалась кількість осіб, які володіють одним із типів професійної спрямованості залежно від того, чи були вони задіяні в тих чи інших формах допрофесійної підготовки. Виявилося, що студенти, які пройшли повний цикл допрофесійної підготовки, в основному зберігають педагогічну спрямованість протягом усього періоду навчання у вищому закладі. Слід відзначити, що зберігається не тільки абстрактна орієнтація на певний тип діяльності, але й бажання працювати в сільській школі, повернутися в той колектив, який рекомендував студента на навчання.

Відомо, що професійний ідеал є важливим складником готовності студентів до педагогічної діяльності, який впливає на їхню активність у навчанні та професійній підготовці в цілому. Виходячи з рівня знань та уявлень щодо професії вчителя, структури його суб'єктивних (індивідуальних) та професійних якостей, студент аналізує зміст навчального процесу і залежно від розуміння ним логічних законів приймає певну стратегію поведінки, яка формується під тиском зовнішніх або внутрішніх факторів, основаних на саморегуляції. Тому наявність та рівень сформованості професійного ідеалу $є$ важливою умовою ефективності професіоналізації, головним мотивом самовдосконалення вчителя.

У дослідженні (Пивовар, \& Семиченко, 1989b) нами була реалізована програма вивчення професійних ідеалів школярів, абітурієнтів, студентів, незалежно від їх навчання у системі допрофесійної підготовки. Оцінка рівня сформованості профідеалів здійснювалася за допомогою методики, розробленої В. А. Семиченко.

Методика відбору емпіричних даних передбачала декілька етапів. Учасникам експерименту пропонувалося у відкритій формі відповісти на за- питання: «Які якості, на Вашу думку, необхідні для успішної професійної діяльності в обраній Вами галузі?» Відкрита форма відповіді ускладнювала процес опрацювання результатів, але підвищувала прогностичність методики, давала можливість виявити індивідуальні особливості та загальні тенденції формування професійних ідеалів у різних групах опитаних, при цьому дозволяючи проаналізувати відповіді наступним чином. Розраховувався об'єм професійних ідеалів, притаманних у середньому кожній групі. Це дозволило визначити кількість структурних одиниць, які постійно включаються у відповіді, однак не давало інформації про змістову внутрішню будову ідеалів. Тому додатково проводилася така процедура опрацювання одержаних даних:

1. У кожній групі перелік якостей диференціювався за такими блоками: спрямованість особистості учителя (X1); педагогічні здібності, елементи педагогічної майстерності (X2); особливості характеру й емоційно-вольової сфери (X3); особливості пізнавальної діяльності вчителя (X4); загальний розвиток особистості (X5).

2. Для кожного блоку були розраховані умовні коефіцієнти, які визначалися через відношення кількості змістових одиниць, що ввійшли в цей блок, до кількості учасників опитування у кожній конкретній групі. Ці коефіцієнти відображали вагомість відповідного блоку у структурі професійного ідеалу. Одержані результати пропонувалися у вигляді математичної моделі:

$\mathrm{Y}=\mathrm{K} 1 \mathrm{X} 1+\mathrm{K} 2 \mathrm{X} 2+\mathrm{K} 3 \mathrm{X} 3+\mathrm{K} 4 \mathrm{X} 4+\mathrm{K} 5 \mathrm{X} 5$,

де $\mathrm{Y}$ - узагальнений професійний ідеал;

К1...К5 - коефіцієнти вагомості кожного блоку; 
Х1...Х5 - блоки структури професійного ідеалу.

За допомогою охарактеризованої методики збору та опрацювання емпіричного матеріалу перевірялася ефективність системи допрофесійної підготовки, що впроваджувалася в Полтавському педінституті. Зіставлення велося між такими групами:

Школярі десятих (на той час - випускних) класів полтавських шкіл, які не орієнтовані на професію вчителя як життєву перспективу.

Школярі десятих класів, які орієнтуються на професію вчителя (бажаючі поступити в педвузи), але не займаються цілеспрямованою підготовкою для реалізації цього наміру (пасивно орієнтовані).

Учні десятих класів, яких спрямовували на педагогічну професію протягом багатьох років (звичайно, розпочавши цю роботу з молодших класів) i, які займаються самоосвітою та самопідготовкою, але не задіяні систематичною допрофесійною підготовкою.

Школярі, які навчаються у факультативі «Юний педагог» під керівництвом учителя в сільській школі.

Школярі, які навчаються на «Факультеті майбутнього вчителя» при природничому факультеті ПДПІ за узагальненою програмою (переважають аудиторні лекційні заняття).

Школярі, що працюють в експериментальному факультативі «Юний педагог» (II ступень підготовки) при кафедрі педагогічної майстерності ПДПІ.

Школярі, які беруть участь в експериментальній школі «Юний педагог» - III ступінь 3 перевагою індивідуальних форм роботи.

Учні педагогічних класів при Карагандинському університеті.

Учні педагогічних класів шкіл м. Миколаєва.

Учні педагогічних класів шкіл м. Джанкоя.

Учні педагогічних класів шкіл м. Луганська.

Учні педагогічних класів при Сиктивкарському університеті.

Учні педагогічних класів шкіл м. Саранська.

Порівняння результатів 1-7 груп дозволяє зробити висновок, чи має впорядкована система допрофесійної підготовки результативність у плані розвитку особистості слухачів, та які організаційні форми дозволяють досягти кращих результатів. Зіставлення даних 4-13 груп допомагає виявити, чи має використана у процесі експерименту система переваги у порівнянні з іншими формами. У таблиці 1 запропоновані одержані кількісні параметри:

Таблиця 1

Результативність досліджуваної системи допрофесійної підготовки

\begin{tabular}{|c|c|c|c|c|c|c|}
\hline \multirow{2}{*}{ Групи } & \multicolumn{5}{|c|}{ Блоки } & \multirow{2}{*}{$\begin{array}{l}\text { Середній об’єм } \\
\text { професійного } \\
\text { iдеалу }\end{array}$} \\
\hline & $\mathrm{X} 1$ & $\mathrm{X} 2$ & $\mathrm{X} 3$ & $\mathrm{X} 4$ & X5 & \\
\hline 1 & 0,03 & 0,7 & 2,8 & 0,03 & 0,03 & 3,6 \\
\hline 2 & 0,3 & 0,8 & 2,6 & 0 & 1,15 & 3,85 \\
\hline 3 & 0,6 & 1,0 & 3,5 & 0,7 & 0,5 & 6,3 \\
\hline 4 & 0,5 & 1,1 & 3,3 & 0,2 & 0,3 & 5,4 \\
\hline 5 & 0,9 & 2,0 & 2,5 & 0,05 & 0,5 & 5,95 \\
\hline 6 & 1,1 & 3,3 & 3,5 & 0 & 0,2 & 8,1 \\
\hline 7 & 2,0 & 2,0 & 4,0 & 0,5 & 0,5 & 9,0 \\
\hline 8 & 0,8 & 0,8 & 3,0 & 0,25 & 0,05 & 4,9 \\
\hline 9 & 0,2 & 1,3 & 3,0 & 0,1 & 0,1 & 4,7 \\
\hline 10 & 1,1 & 2,0 & 3,5 & 0,7 & 3,0 & 7,6 \\
\hline 11 & 0,5 & 1,9 & 3,3 & 0,3 & 0,2 & 6,2 \\
\hline 12 & 0,75 & 0,9 & 2,3 & 0,3 & 0,05 & 4,3 \\
\hline 13 & 0,75 & 0,6 & 2,1 & 0,05 & 0,15 & 3,65 \\
\hline
\end{tabular}

3 одержаних даних чітко видно, що учні не орієнтовані на професію вчителя як життєву перспективу, володіють мінімальним показником насиченості професійного ідеалу, не бачать складності й різнобічності педагогічної діяльності. Структурний склад їхніх ідеалів бідний, малозмістовний. Пасивна орієнтація на педагогічну роботу не сприяє якісним змінам у професійному ідеалі (дані по 2 групі). Дещо інша тенденція спостерігається в групі школярів, які протягом довгого часу були орієнтовані на професію вчителя та, які систематично займалися самовихованням і самоосвітою. Більш глибоке знайомство зі змістовим та функціональним складом педагогічної діяльності призводить до суттєвого росту об'єму профідеалів (5,9 якостей у порівнянні з 3,85 і 3,6 у попередніх групах).

Міжгрупове зіставлення показників, одержаних від школярів, які навчаються в факультативі «Юний педагог» за скороченою програмою (зокрема 3 додатковим уключенням у роботу «Факультету майбутнього вчителя» при університеті), показує, що ця форма підготовки характеризується також певною ефективністю, хоча за ступенем впливу відрізняється від процесу професійного самовиховання школярів. Можна зробити висновок, що відсутність систематичного предметного профілювання, абстрактна орієнтація школярів на професію вчителя, яка не підкріплюється відповідною діяльністю, перевага групових аудиторних форм над індивідуальними, скорочення циклів навчання перешкоджають появі різкого якісного стрибка у формуванні психологічних основ професійної діяльності у порівнянні з самостійними, навіть невпорядкованими формами роботи. 
Найбільш високі результати були одержані в групі школярів, які навчалися в експериментальному факультативі «Юний педагог», що працював за суворо повною програмою при кафедрі педагогічної майстерності ПдПІ імені В. Г. Короленка. Порівняння даних у 6-7 групах свідчить, що у процесі переходу на вищий ступінь навчання відмічається і подальший розвиток (зміна) аналізованого показника.

Дослідження профідеалу у студентів першого курсу зафіксувало, що до кінця навчального року у групі, яка має допрофесійну підготовку, він дещо зростає (6,1 проти 5,7). Аналіз змістового складу моделей також підтвердив тенденцію випереджаючого розвитку професійного ідеалу в експериментальному факультативі, який ведеться за предметно-орієнтованою програмою. У процесі навчання у вузі група студентів, які пройшли допрофесійну підготовку, проявляють більшу орієнтованість на знання, уміння, навички, спеціальні здібності (розрив 3 іншою групою в 2 рази) (Пивовар, \& Дидора, 1985; Пивовар, \& Семіченко, 1989).

Організація експериментальної роботи здійснювалась у рамках Цільової комплексної програми «Вчитель», базові вимоги якої співзвучні з тими, що заявлені в Концепції Нової української школи. Задовго до появи інноваційних тенденцій, що покликані поставити нашу освіту на європейський рівень, гуманістично зорієнтовані педагогічні пошуки наближалися до вирішення завдання забезпечити оптимальні умови для розвитку дитини в освітньому процесі, і разом із тим - і для професійного саморозвитку вчителя, основи якого закладалися 3 перших днів навчання у вищій школі.

Участь автора у роботі цієї системи полягала в методичному керівництві вчителями шкіл, які вели факультативи (підготовка й поширення методичних посібників, організація навчання) та здійсненні формуючого експерименту, у межах якого розроблялись і реалізувалися оптимальні програми організації факультативу.

Усебічний експериментально-педагогічний аналіз системи факультативної підготовки та їі ролі у виборі учнями учительської професії дозволив зробив такі висновки:

1. Одним із способів підвищення ефективності системи підготовки педагогічних кадрів може виступати рання профорієнтація учнів. Експериментально доведено, що чим раніше й послідовніше проводиться цілеспрямована підготовка школярів до вибору педагогічної професії, тим результативнішими виявляються її наслідки. У молоді шкільного віку ця тенденція простежується і в процесі самостійної роботи, і в момент залучення ії у сферу функціонування допрофесійної підготовки.

2. Система допрофесійної підготовки вчителя має (і активно ними користується) поточні оцінки своєї ефективності: зокрема, використані в дослідженні психологічні показники розвитку особистості майбутніх педагогів (стійкість професійної спрямованості, сформованість професійних ідеалів, прийняття активної рольової позиції вчителя) та відхилення локус-контролю в бік інтернальності.

\section{Список використаних джерел}

Нова украӥнська школа. Конщептуальні засади реформування середньої школи. (2016). Взято 3 https://www.kmu.gov.ua/storage/app/media/reforms/ukrainska-shkola-compressed.pdf.

Пивовар, Н. М. (1989а). Влияние психолого-педагогических факторов на учебную деятельность и образ жизни студентов вуза. Здоровый образ жизни: прикладные психологические проблемы. Сыктывкар.

Пивовар, Н. М., \& Семиченко, В. А. (1988). Влияние профессионального идеала на учебную активность студентов педвуза. Психологические аспекты пропаганды здорового образа жизни (С. 103-107). Сыктывкар.

Пивовар, Н. М., \& Семиченко, В.А.(1989b). Психологічні можливості системи допрофесійної підготовки у формуванні контингенту студентів педвузу. Вища і середня педагогічна освіта: наук.-метод. зб. (Вип. 14, С. 95-99). Київ: Вища школа.

Пивовар, Н. М., \& Дидора, М. И. (1985). Факультатив «Юный педагог» в системе допрофессиональной подготовки учителя. Пути совершенствования психолого-педагогической подготовки учителя в свете основных направлений реформы общеобразовательной и профессиональной школьь (С. 133-135). Полтава, 1985.

Семиченко, В. А. (1997) Порівняльний аналіз цінностей педагогічної діяльності та професійної підготовки вчителів. В кн. О. В. Сухомлинська (Ред.), Цінності освіти і виховання: наук.-метод. зб. (С. 135-200). Київ.

Семиченко, В. А. (1989). Психологические основы профессиональной подготовки студентов вуза. Полтава: Гос. пед. ин-т имени В. Г. Короленко.

\section{References}

Nova ukrainska shkola. Kontseptualni zasady reformuvannia serednoi shkoly [New Ukrainian School. Conceptual principles of secondary school reform]. https://www.kmu.gov.ua/storage/app/media/reforms/ukrainska-shkola-compressed.pdf [in Ukrainian].

Pivovar, N. M. (1989a). Vliianie psikhologo-pedagogicheskikh faktorov na uchebnuiu deiatelnost i obraz zhizni studentov vuza [The influence of psychological and pedagogical factors on educational activities and lifestyle of university students]. In Zdorovyi obraz zhizni: prikladnye psikhologicheskie problem [Healthy lifestyle: applied psychological problems]. Syktyvkar [in Russian].

Pivovar, N. M., \& Semichenko, V. A. (1988). Vliianie professionalnogo ideala na uchebnuiu aktivnost studentov pedvuza [The influence of professional ideal on the educational activity of pedagogical students]. In Psikhologicheskie aspekty propagandy zdorovogo obraza zhizni [Psychological aspects of promoting a healthy lifestyle] (pp. 103-107). Syktyvkar [in Russian].

Pivovar, N. M., \& Didora, M. I. (1985). Fakultativ «Iunyi pedagog» v sisteme doprofessionalnoi podgotovki uchitelia [Optional "Young teacher" in the system of pre-vocational teacher training]. Puti sovershenstvovaniia psikhologo- 
pedagogicheskoi podgotovki uchitelia $v$ svete osnovnykh napravlenii reformy obshcheobrazovatelnoi $i$ professionalnoi shkoly [Ways to improve the psychological and pedagogical training of teachers in the light of the main directions of reform of secondary and vocational schools] (pp. 133-135). Poltava [in Russian].

Pyvovar, N. M., \& Semychenko, V. A. (1989b). Psykholohichni mozhlyvosti systemy doprofesiinoi pidhotovky u formuvanni kontynhentu studentiv pedvuzu [Psychological possibilities of the system of pre-vocational training in the formation of a contingent of students of high school]. In Vyshcha i serednia pedahohichna osvita [Higher and secondary pedagogical education]: nauk.-metod. zb. (Is. 14, pp. 95-99). Kyiv: Vyshcha shkola [in Ukrainian].

Semychenko, V. A. (1997) Porivnialnyi analiz tsinnostei pedahohichnoi diialnosti ta profesiinoi pidhotovky vchyteliv [Comparative analysis of values of pedagogical activity and professional training of teachers]. In O. V. Sukhomlynska (Ed.), Tsinnosti osvity $i$ vykhovannia [Values of education and upbringing]: nauk.-metod. zb. (pp. 135-200). Kyiv [in Ukrainian].

Semichenko, V. A. (1989). Psikhologicheskie osnovy professionalnoi podgotovki studentov vuza [Psychological foundations of professional training of university students]. Poltava: Gos. ped. in-t imeni V. G. Korolenko [in Russian].

\section{PIVOVAR N.}

Poltava V. G. Korolenko national pedagogical University, Ukraine

\section{DIAGNOSTIC POSSIBILITIES OF A PROFESSIONAL IDEAL IN THE SYSTEM OF PRE-PROFESSIONAL TRAINING OF A NEW UKRAINIAN SCHOOL TEACHER}

The article deals with the possibility of using for the diagnostic purpose of the level of formation of the professional ideal of the future teacher as the main motive of self-improvement in various systems of pre-vocational training.

It describes the experimental work carried out within the framework of the Teacher Comprehensive Target Program, the basic requirements of which are in line with those stated in the Concept of the New Ukrainian School. Long before the emergence of innovative trends designed to put our education at the European level, humanistic-oriented pedagogical research was approaching the task of providing optimal conditions for the development of the child in the educational process, and at the same time - for the professional self-development of the teacher, whose foundations were laid from the first days studying in high school.

The author argues that one of the ways to increase the effectiveness of the system of training of pedagogical staff can be early guidance of students. It is experimentally proved that the earlier and the more purposeful preparation of pupils for the choice of pedagogical profession is carried out, the more effective are its consequences. In school-age youth, this tendency is observed both in the process of independent work, and at the moment of its involvement in the sphere of functioning of pre-vocational training. The system of pre-professional teacher training is based on current assessments of its effectiveness: in particular, the psychological indicators of the development of the personality of future teachers (stability of professional orientation, formation of professional ideals, acceptance of an active role of the teacher) and deviation of locus-control towards the use of the locus.

Keywords: professional ideal; pre-professional teacher training; students' professional orientation; mathematical model of professional ideal

Стаття надійшла до редакції 18.04.2019 p. 